\title{
Attitude towards Marriage and Life Satisfaction among Mid Adults
}

\author{
Shefali S K ${ }^{1}$, Navya Shree G C
}

\section{ABSTRACT}

Middle age is one of the most important periods of human life as it is the time of transitions in terms of family responsibilities, physical health, social interests and hobbies, etc. People in this stage want to enjoy the success in personal and professional lives. Attitude towards marriage plays a very important role in life in determining ones life satisfaction. As far middle age is concerned job, socialization, marriage, and family are the contributing factors for life satisfaction in them. The objective of the study was to find the relationship between attitude towards marriage and Life Satisfaction among mid adults. The sample comprised of 60 mid adults belonging to the age range of 35 to 50 years from rural and urban areas. The tools used to asses Attitude towards marriage and life satisfaction were Marriage attitude scale (Pramod Kumar,1988) and Life Satisfaction scale (Diener, Emmons, Larsen and Griffin, 1985) respectively. Results were analyzed using Two way Analysis of Variance and Pearson coefficient of correlation. Result showed that there is no significant gender difference in attitude towards marriage and life satisfaction among mid adults. There is no significant difference between urban and rural mid adults in their attitude towards marriage and level of life satisfaction. The findings indicated that the two variables are independent of each other and there is no significant relationship between the two.

\section{Keywords: Life Satisfaction, Marriage Attitude, Mid Adults}

In Mid age, one is required to have a proper attitude, skill and temperament towards marriage to endure success in marriage. Ruch (1970) rightly says that being the right person is more a matter of becoming the right person, but for a happy marriage right attitude is required. The ease in becoming the right person to a great extent depends on the attitude one holds towards marriage (Srivasta, 1974). Throughout the world and amongst many different cultures, attitudes towards marriage are diverse (Goslin, 2014). In India marriage is considered a lifelong partnership. It is

\footnotetext{
${ }^{1}$ II MSc Psychology Student, Department of Post Graduate Studies and Research in Psychology, SDM College, Ujire, India

${ }^{2}$ Assistant Professor, Department of Post Graduate Studies and Research in Psychology, SDM College, Ujire, India

*Responding Author

(C) 2016 I Shefali S, N Shree; licensee IJIP. This is an Open Access Research distributed under the terms of the Creative Commons Attribution License (http://creativecommons.org/licenses/by/2.0), which permits unrestricted use, distribution, and reproduction in any Medium, provided the original work is properly cited.
} 


\section{Attitude towards Marriage and Life Satisfaction among Mid Adults}

the rock on which the family is built, and which, in turn, is the foundation of society. Basically, marriage is a social and legal contract. As divorce has become a modern-day norm, it is expected that the present-day mid adult tends to have a distrust of marriage as an institution. Shurts and Myers (2011) stated that individuals develop their attitudes based on a variety of experiences, including messages received from the family, the media, religious values and groups of friends. According to Akers - woody (2004) positive parental and family dynamics are related to more positive attitudes to marriage. A study by Riggio and Weiser (2008) which was a replication of a study of that of Prislin and Ovellette (1996) showed that more embedded marriage attitudes are more predictive of evaluations of general marriage issues and relationship scenarios than less embedded attitudes. Attitudes towards marriage are influenced by many other factors in society, such as divorce, culture and religion. (Akers-Woody, 2004). Therefore, it is not surprising that attitudes toward marriage can be both positive and negative depending of the experience of the individual. Bharsakharte, (2013) found that people come with different opinions and in modern society today, individuals are against marriage, as it considered an old concept and way of life that is no longer workable in today's complex world(Bharsakharte,2013). It is important to view marriage as both positive and negative.

The negative side of marriage may alter children's attitudes toward marriage. Research within the area of martial attitudes among mid adults in respect to gender differences, has produced conflicting results. Research by Braaten and Rosén (1998) and Larson, Benson, Wilson and Medora (1998) found no gender differences in marital attitudes among adults.

Research have shown that, because of hectic work schedule, Urban spouse are busy with their own carrier as well as their own friends circle and also they have also shown that rural mid adults have positive attitude towards marriage, when compared to urban mid adults.

Most of mid- adults now a day enjoy relatively good health and stabilized finances which helps them to feel satisfied with their life. Life satisfaction is the sense of contentment which an individual is getting from his life. This can be an opportunity for them to pursue their own interests and get more life satisfaction. Blanchflower and Oswald (2008) reported a significant quadratic effect of age on the happiness and life satisfaction. According to their research increased work demands, parenting adolescents, empty nesting, caring for aging parents, financial issues and retirement are some of the concerns that increases stress in mid- adults. But coping with those stressful life situations successfully brings a sense of satisfaction among mid adults about their life.

As far as middle age is concerned following parameters can be taken into account to explain the life satisfaction:

1. Job: Work satisfaction is at its peak in mid life years and the quality of work performance remains high, despite of decline in some cognitive or physical skills. Crohan, Antonucci 


\section{Attitude towards Marriage and Life Satisfaction among Mid Adults}

et al. (1989) in their study on Americans and Africo- American men and women indicated that job satisfaction is positively related to life satisfaction for all four groups.

2. Marital life: It is likely that mid aged partners' identification of successful problemsolving strategies contribute to the sense that they have control over their relationship. Zainah et al. (2012) study on mid- adult married couple indicated that length of marriage and income has great influence on life satisfaction.

3. Family : Middle age is also referred as 'sandwich generation' as family relationships in the middle age extend in both directions: relationship with grown children as well as with aging parents

4. Socialization: In the process of socialization, adults prepare for a transition in role; it also involves identifying the new norms and expectations associated with such new social role as in-laws and grand parents. Mid adults have more concern for law, traditions, and cultural values and restricted acceptance against too rapid cultural change (Nema, 2015)

Several factors like family environment, work condition, social environment, financial status, marital relation etc. which affect married couples' adjustment and life satisfaction. There are several studies conducted on these correlates in different countries and societies. But still there is lacking of a dedicated study on factors affecting mid-aged couple's adjustment and satisfaction in Indian perspective which need to be addressed (Nema, 2015).

Study done by Chen.et.al (2006), showed that urban adults have reported more satisfaction with their lives, when compared with rural adults. Findings are consistent with some previous studies that indicated the importance of financial strain, depressive symptoms, filial piety, and accessibility of health services to life satisfaction among the adults in both urban and rural areas. This study also demonstrated the importance of age and family financial exchange to the life satisfaction of urban adults.

The previous researches and review of literature indicates that there is no gender difference in attitude towards marriage and life satisfaction but rural population have positive attitude towards marriage when compared to urban population.

\section{METHOD}

\section{Objective:}

1. To find the relationship among Marriage attitude and Life Satisfaction in mid adults.

\section{Hypothesis:}

1. There is no significant gender difference in the level of Life Satisfaction and Marital attitude among mid adults.

2. There is no significant difference between rural and urban mid adults in Life satisfaction and Marital attitude 


\section{Attitude towards Marriage and Life Satisfaction among Mid Adults}

3. There is no significant relationship between Life satisfaction and Marital attitude among mid adults.

\section{Independent variables:}

Gender (males and females), Locality (urban and rural)

\section{Dependent variables:}

Attitude towards marriage and life satisfaction

\section{Research Design:}

The design used is $2 * 2$ factorial design.

\section{Sampling:}

The purposive sampling method was adopted. Sample for the study consisted of 60 mid adults, 30 from urban area and 30 from rural area. Both rural and urban sample consisted of 30 males and females each, who were married and had children. The mid adults of the age 35 to 50 years are considered for the study. For the present study the data was collected from the residents of Madanthyar, Agumbe and Uppinangadi, of Karnataka, representing the rural sample and residents of Bengaluru representing the urban sample.

\section{Inclusion criteria:}

1. Mid adults who belong to the age group of 35- 50 years

2. Married men and women with children

\section{Exclusion criteria:}

1. Divorced, separated and widowed individuals.

\section{Tools:}

1. Life satisfaction scale (Diener, Emmons, Larsen and Griffin, 1985): Life satisfaction scale consists of 35 items and is a five point rating scale: always, often, sometimes, seldom (rarely), and never. The score ranges from 35 to 175 . The higher score indicates high level of life satisfaction.

2. Marriage Attitude Scale (Pramod Kumar,1988): The Marriage Attitude Scale consists of 38 highly sensitive 'yes', 'no', 'doubtful' type of items. The respondents may answer these statements on the uniform three point scale. The questionnaire consists of both positive and negative items. The reliability co- efficient values are 0.88 and 0.91 for mixed group, males and females respectively and thus the co-efficient of reliability are sufficiently high and scale can be consider as reliable for use. The present scale is sufficiently valid for measuring marriage attitude. 


\section{Attitude towards Marriage and Life Satisfaction among Mid Adults}

\section{Procedure:}

The participants were met individually. They were seated comfortably and the rapport was established. The purpose of the study was explained to them and their consent was sought to participate in the study. After collecting the socio demographic details, Marriage attitude Scale and Life Satisfaction Scale was given to the participants with relevant instructions. After completion, the scale was collected and participants were thanked for their participation and cooperation.

\section{RESULT AND DISCUSSION}

The hypothesis of the study was tested using two way ANOVA and Pearson co-efficient of correlation.

Table 1: Summary of two-way ANOVA for Marriage Attitude among mid adults from rural and urban area

\begin{tabular}{|l|l|r|r|l|l|}
\hline $\begin{array}{l}\text { Sources of } \\
\text { variance }\end{array}$ & $\begin{array}{l}\text { Sum } \\
\text { Square }\end{array}$ & \multicolumn{1}{l|}{ Df } & Mean Square & F-Value & Sig \\
\hline $\begin{array}{l}\text { Between } \\
\text { Locality(A) }\end{array}$ & 106.667 & 1 & 106.667 & 1.496 & .226 \\
\hline $\begin{array}{l}\text { Between } \\
\text { Gender(B) }\end{array}$ & 9.600 & 1 & 9.600 & .135 & .715 \\
\hline A*B & 6.667 & 1 & 6.667 & .093 & .761 \\
\hline Error & 3994.000 & 56 & 71.321 & & \\
\hline
\end{tabular}

Table 2: Mean and Standard Deviation on Marriage attitude among mid adults

\begin{tabular}{|l|l|l|l|}
\hline Group & Gender & Mean & Standard Deviation \\
\hline \multirow{4}{*}{ Urban } & Male & 60.07 & 8.498 \\
\cline { 2 - 4 } & Female & 61.53 & 9.812 \\
\cline { 2 - 4 } & Total & 60.80 & 9.049 \\
\hline \multirow{4}{*}{ Rural } & Male & 63.40 & 8.467 \\
\cline { 2 - 4 } & Female & 63.53 & 6.717 \\
\cline { 2 - 4 } & Total & 63.47 & 7.510 \\
\hline \multirow{5}{*}{ Total } & Male & 61.73 & 8.505 \\
\cline { 2 - 4 } & Female & 62.53 & 8.324 \\
\cline { 2 - 4 } & Total & 62.13 & 8.353 \\
\hline
\end{tabular}

The hypothesis stating that the rural and urban mid adults do not differ in their attitude towards marriage and there is no gender difference in the attitude towards marriage was tested using two way ANOVA. The table 1 indicates that the F value for locality $(0.226)$ is not significant. This shows that the rural and urban mid adults do not differ significantly in their attitude towards

(c) The International Journal of Indian Psychology, ISSN 2348-5396 (e)| ISSN: 2349-3429 (p) | 134 


\section{Attitude towards Marriage and Life Satisfaction among Mid Adults}

marriage. F value of the gender (0.715) is not significant which shows that there is no significant gender difference in the marriage attitude. $\mathrm{F}$ for interaction is also not significant. Thus it approves the assumed null hypothesis. A contradictory result was obtained by a study, titled "Marriage practices in contemporary China: a comparative study of urban and rural marriages in Taiwan" conducted by Wei and Reischi (1982) and the results indicated that more traditional attitude towards marriage is noted in rural areas.

Table 3: Summary of two-way ANOVA for Life satisfaction among mid adults from rural and urban area

\begin{tabular}{|l|l|l|l|l|l|}
\hline $\begin{array}{l}\text { Source of } \\
\text { Variance }\end{array}$ & $\begin{array}{l}\text { Sum of } \\
\text { Squares }\end{array}$ & Df & Mean Square & F-Value & Sig \\
\hline $\begin{array}{l}\text { Between } \\
\text { Locality(A) }\end{array}$ & 147.267 & 1 & 147.267 & .506 & .480 \\
\hline $\begin{array}{l}\text { Between } \\
\text { Gender(B) }\end{array}$ & 4.267 & 1 & 4.267 & .015 & .904 \\
\hline AB & 5.400 & 1 & 5.400 & .019 & .892 \\
\hline Error & 16310.000 & 56 & 291.250 & & \\
\hline
\end{tabular}

Table 4: Mean and SD of mid adults on life satisfaction scale.

\begin{tabular}{|l|l|l|c|}
\hline Group & Gender & Mean & Standard Deviation \\
\hline \multirow{5}{*}{ Urban } & Male & 142.47 & 15.583 \\
\cline { 2 - 4 } & Female & 143.60 & 16.634 \\
\cline { 2 - 4 } & Total & 143.03 & 15.847 \\
\hline \multirow{3}{*}{ Rural } & Male & 139.93 & 18.065 \\
\cline { 2 - 4 } & Female & 139.87 & 17.864 \\
\cline { 2 - 4 } & Total & 139.90 & 17.652 \\
\hline \multirow{3}{*}{ Total } & Male & 141.20 & 16.627 \\
\cline { 2 - 4 } & Female & 141.73 & 17.066 \\
\cline { 2 - 4 } & Total & 141.47 & 16.706 \\
\hline
\end{tabular}

The hypothesis stating that the rural and urban mid adults do not differ in their level of life satisfaction and there is no gender difference in the level of life satisfaction was tested using two way ANOVA. The F value (0.480) for locality is not significant. This shows that there is no significant difference in life satisfaction among rural and urban mid adults. $\mathrm{F}$ for gender (0.904) and interaction (0.892) is not significant which indicates that there is no significant difference in life satisfaction among males and females. Thus the null hypothesis is accepted. A study done by Cheng et al (2006), supports the results as well as contradicts and the research reveals that there is no gender difference in life satisfaction of adults in China but urban adults are more satisfied with their lives, when compared to rural adults in China.

(c) The International Journal of Indian Psychology, ISSN 2348-5396 (e)| ISSN: 2349-3429 (p) | 135 
Attitude towards Marriage and Life Satisfaction among Mid Adults

Table 5: The coefficient of correlation between Marriage attitude and life satisfaction.

\begin{tabular}{|l|l|l|}
\hline & Marriage Attitude & Life satisfaction \\
\hline Marriage Attitude & 1 & 0.244 \\
\hline Life satisfaction & 0.244 & 1 \\
\hline
\end{tabular}

The hypothesis states that there is no significant relationship between life satisfaction and attitude towards marriage was tested using Pearson coefficient of correlation. Pearson coefficient of correlation is 0.244 which is not significant which indicates that there is no significant relationship between life satisfaction and attitude towards marriage. Thus it supports the assumed hypothesis which states that there is no significant relation between self efficacy and life satisfaction. A contradictory result was obtained by a study, conducted by Kim and Jung (2015) and the analysis revealed that attitudes toward marriage significantly differed by gender and were positively correlated with life satisfaction.

\section{SUMMARY AND CONCLUSION}

Obtained result of the present research study shows that there is no significant gender difference in attitude towards marriage and life satisfaction among mid adults. There is no significant difference between urban and rural mid adults in their attitude towards marriage and level of life satisfaction. The findings indicated that the two variables are independent of each other and there is no significant relationship between them.

\section{LIMITATIONS OF PRESENT STUDY}

Sample was drawn only from limited area i.e. Bangalore (Urban) and Dakshina Kannada (Rural) hence generalization is limited in its scope.

\section{SCOPE FOR FURTHER STUDY}

The generalizability can be improved by considering large sample in urban areas as well as rural areas and also divorced, separated, mid adults with children, without children, employed and socio economic status can also be taken into consideration.

\section{REFERENCES}

Ann Creighton Zollar and J. Sherwood Williams (Feb, 1987). The Contribution of Marriage to the Life Satisfaction of Black Adults. Journal of Marriage and Family; Vol. 49, No. 1 ,pp. 87-92

Baron, R.A and Branscombe. (2015) .Social Psychology (13th ed). India: Pearson Publications. Baumgardner, S and Crothers.M. (2015). Positive Psychology. India: Dorling, Kindersley(India) pvt.ltd.

Bookwala, J. (2012) Handbook of Families and Aging, 2nd ed. (pp. 91-123). Santa Barbara, CA: Praeger.

Crothers, S. B. (2009). Positive psychology. New Delhi: Dorling Kindersley. 


\section{Attitude towards Marriage and Life Satisfaction among Mid Adults}

Karen L. Siedlecki , Elliot M. Tucker-Drob, Shigehiro Oishi and Timothy A. Salthouse. (July 2008). Life satisfaction across adulthood: different determinants at different ages.

Lindy Williams and Michael Philip Guest. (Spring 2005). Attitudes Toward Marriage Among the Urban Middle-Class in Vietnam, Thailand, and the Philippines. Journal of Comparative Family Studies; Vol. 36, No. 2, pp. 163-186.

Nema, S. (February 2015). Review of literature on Correlates of Adjustment and Life Satisfaction among middle aged Married Couple. International Journal of Scientific and Research Publications; 5 (2); ISSN 2250- 3153.

Singh, A.K. (2013). Tests Measurements and Research Methods in Behavioural Sciences. Patna: Bharati Bhawan Publishers.

Snyder, R.C; Lopez, J.S and Jennifer P T. (2011). Positive Psychology (2nded). New Delhi: SAGE publication India pvt. Ltd

Sorensen,D.L.J. (21 Jan 2013). Rural-Urban Differences in Life Satisfaction: Evidence from the European Union. Regional Studies; Volume 48, Issue 9, pages 1451-1466.

The Journal of Positive Psychology, Vol. 3, No. 3,pp. 153-164.

How to cite this article: Shefali S, N Shree (2016), Attitude towards Marriage and Life Satisfaction among Mid Adults, International Journal of Indian Psychology, Volume 3, Issue 3, No. 11, DIP: 18.01.203/20160303, ISBN: 978-1-365-21307-6 